\title{
Potencial in vitro de Bacillus spp. no controle de Curtobacterium flaccumfaciens pv. flaccumfaciens em feijoeiro-comum
}

\author{
Evelynne Urzêdo Leão ${ }^{1}$; Júlio Cesar da Silva ${ }^{1}$; Fabíola Rodrigues Medeiross ${ }^{1}$ Gabriela Silva Santa Rosa Macêdo²; \\ Gentil Cavalheiro Adorian ${ }^{3}$; Antonio Carlos Maringoni ${ }^{1}$
}

\begin{abstract}
${ }^{1}$ Departamento de Proteção Vegetal, Faculdade de Ciências Agronômicas, FCA-UNESP, CEP 18610-307, Botucatu, SP; ${ }^{2}$ Departamento de Horticultura, Faculdade de Ciências Agronômicas, FCA-UNESP, CEP 18610-307, Botucatu, SP; ${ }^{3}$ Doutor em Fitotecnia (Esalq/USP), Professor da Faculdade Católica do Tocantins, CEP 77061-002, Palmas - TO

Autor para correspondência: Evelynne Urzêdo Leão (evelynnegpi@gmail.com )
\end{abstract}

Data de chegada: 28/08/2015. Aceito para publicação em: 24/08/2016.

$10.1590 / 0100-5405 / 2120$

\section{RESUMO}

Leão, E.U.; Silva, J.C.; Medeiros, F.R.; Macêdo, G.S.S.R.; Adorian, G.C.; Maringoni, A.C. Potencial in vitro de Bacillus spp. no controle de Curtobacterium flaccumfaciens pv. flaccumfaciens em feijoeiro-comum. Summa Phytopathologica, v.42, n.4, p.360-362, 2016.

O feijoeiro-comum (Phaseolus vulgaris) é uma cultura de grande relevância na alimentação da população brasileira. A murcha-de-curtobacterium ou murcha bacteriana, causada por Curtobacterium flaccumfaciens pv. flaccumfaciens (Cff), é uma doença vascular que acomete o feijoeiro causando danos significativos. Neste contexto, o objetivo deste trabalho foi avaliar a ação in vitro de Bacillus spp. na inibição de dois isolados de Cff, colonização do sistema radicular e desenvolvimento de plântulas de feijoeiro-comum. Foram realizados dois ensaios in vitro para verificar a atividade antagônica dos isolados Bacillus licheniformis, B. subtilis e B. subtilis + B. lichenformis a dois isolados de Cff. Todos os isolados de Bacillus spp. apresentaram inibição no crescimento dos isolados de Cff. Não foi observada a colonização das raízes das plântulas de feijoeiro-comum, pelos isolados bacterianos avaliados.

Palavras-chave: Phaseolus vulgaris, Murcha-de-curtobacterium, Controle Biológico, Antagonismo Bacteriano

\section{ABSTRACT}

Leão, E.U.; Silva, J.C.; Medeiros, F.R.; Macêdo, G.S.S.R.; Adorian, G.C.; Maringoni, A.C. In vitro potential of Bacillus spp. in the control of Curtobacterium flaccumfaciens pv. flaccumfaciens in common bean. Summa Phytopathologica, v.42, n.4, p.360-362, 2016.

The common bean (Phaseolus vulgaris) constitutes a very important crop in the feeding of the Brazilian population. The curtobacterium wilt or bacterial wilt, caused by Curtobacterium flaccumfaciens pv. flaccumfaciens (Cff), is a vascular disease that affects the common bean, leading to significant damage. In this context, the aim of this study was to evaluate the in vitro effect of Bacillus spp. on the inhibition of two Cff isolates, the colonization of the root system and the development of common bean seedlings. Two in vitro assays were performed to verify the antagonistic activity of the isolates Bacillus licheniformis, B. subtilis, and B. subtilis + B. lichenformis against two isolates of Cff. All isolates of Bacillus spp. inhibited the growth of Cff isolates. Common bean seedlings showed no root colonization by the evaluated bacterial isolates.

Keywords: Phaseolus vulgaris, Curtobacterium Wilt, Biological control, Bacterial Antagonism

O feijoeiro-comum (Phaseolus vulgaris L.) é uma cultura de grande relevância na alimentação da população brasileira, sendo o Brasil um dos maiores produtores do mundo. Contudo, a produtividade média do país é baixa, sendo a incidência de doenças um dos principais fatores (1). A murcha-de-curtobacterium ou murcha bacteriana, causada por Curtobacterium flaccumfaciens pv. flaccumfaciens (Cff), é uma doença vascular importante para a cultura do feijoeiro, na qual o seu agente causal sobrevive e é disseminado por sementes (2). Os sintomas típicos da doença, além da murcha, incluem o amarelecimento das folhas, nanismo e morte de plantas (12). A doença encontra-se distribuída em várias áreas produtoras de feijão, principalmente nas regiões Sul, Sudeste e Centro-Oeste e seu controle está baseado somente no uso de sementes sadias, rotação de culturas e cultivares com algum nível de resistência genética $(9,12)$.

O controle biológico de doenças com o uso de microrganismos é uma ferramenta importante para a agricultura. A diversidade de microrganismos existentes, bem como suas relações antagônicas, são ferramentas importantes no controle biológico (7). Bactérias isoladas da rizosfera e rizoplano de plantas podem promover o crescimento das plantas e controlar fitopatógenos de solo, pois são capazes de crescer e colonizar o sistema radicular, que é o sítio de infecção desses patógenos (7). O potencial de controle da murcha-de-curtobacterium do feijoeiro, em condições controladas, via tratamento de sementes com isolados específicos de rizobactérias vem sendo estudado $(4,10)$. Neste contexto, o presente estudo objetivou avaliar a ação inibitória in vitro de Bacillus spp. sobre dois isolados de Cff.

A atividade antagônica in vitro de isolados de $B$. subtilis, $B$. subtilis (isolado AP03), B. licheniformis, B. subitilis + B. licheniformis e Rhizobium sp., cedidas pelo Dr. Wagner Bettiol da Embrapa Meio Ambiente - Jagariúna/SP, foi avaliada contra dois isolados de Cff(Feij2500 e Feij-2628), pertencentes a coleção de bactérias fitopatogências do Laboratório de Bacteriologia Vegetal, DPV/FCA/UNESP Campus de Botucatu. Empregou-se a metodologia descrita por Romero (13) de antibiose por difusão em dupla camada de meio de cultura agarizado. Para tanto, placas de Petri de vidro contendo meio de cultura nutrientesacarose-ágar (NSA) foram semeadas em quatro pontos equidistantes com os isolados de Bacillus spp. Cada isolado foi semeado em cinco placas de Petri e incubado a $28^{\circ} \mathrm{C}$, por 48 horas. As placas foram em 
seguida transferidas para câmara de fluxo laminar, na posição invertida e adicionado $1 \mathrm{~mL}$ de clorofórmio na tampa de cada uma delas, por 30 min., sob luz ultravioleta. As placas permaneceram entreabertas por 30 min., visando a volatilização do clorofórmio remanescente. A seguir foi adicionada uma sobrecamada de $5 \mathrm{~mL}$ de meio NSA fundente, contendo $0,75 \%$ de ágar, ao qual foram incorporados $0,1 \mathrm{~mL}$ de suspensão de cada um dos isolados de Cff. As placas foram mantidas a $28{ }^{\circ} \mathrm{C}$, por 48 horas, e foram medidos os diâmetros perpendiculares dos halos de inibição formados ao redor das colônias inativadas das bactérias (em $\mathrm{cm})$ e classificados conforme Silva et al. (14), em: $+(0-0,9 \mathrm{~cm})$ baixa capacidade de inibição; $++(1,0-1,9 \mathrm{~cm})$ média capacidade de inibição; +++ $(2,0-2,9 \mathrm{~cm})$ alta capacidade de inibição; $++++(>3,0$ $\mathrm{cm})$ muito alta capacidade de inibição.

Sementes de feijoeiro-comum (cultivar Pérola) foram desinfestadas em álcool a $70 \%$, por 2 min. e hiploclorito de sódio a $2 \%$, durante 5 min., enxaguadas em água destilada e esterilizada e imersas separadamente em suspensões bacterianas $\left(10^{8} \mathrm{UFC} / \mathrm{mL}\right)$ dos isolados de bactérias, durante $1 \mathrm{~h}$, e secas em ambiente de laboratório durante $12 \mathrm{~h}$. O tratamento testemunha foi representado por sementes de feijoeiro imersas em água destilada contendo $0,01 \%$ de Tween 20 . Em seguida, oito sementes de cada um dos tratamentos foram transferidas individualmente para tubos de ensaio (25 $\mathrm{mm} \times 150 \mathrm{~mm})$ contendo Phytagel-água (11). Os tubos foram mantidos em B.O.D. a $25^{\circ} \mathrm{C}$, sob fotoperíodo de $12 \mathrm{~h}$, durante 10 dias. Nesse período foi avaliada a emergência das plântulas e no décimo dia de incubação foi avaliada a turbidez do meio Phytagel-água, ao redor das raízes das plântulas, que indicou a colonização do rizoplano (11). As plântulas foram retiradas dos tubos e o comprimento da raiz principal e da parte aérea foi mensurado. Os dados obtidos foram submetidos à análise de variância e as médias comparadas com o teste de Tukey a 5\%.

Todas as bactérias inibiram o crescimento dos dois isolados de Cff avaliados (Tabela 1). B. licheniformis foi o que promoveu maior inibição do crescimento de ambos os isolados do patógeno, com halo de inibição maior que $3 \mathrm{~cm}$ de diâmetro. Também foi possível observar que $B$. subtilis (AP03) promoveu maior inibição do isolado Feij-2500 de
Cff. Nesse tratamento não foi possível observar o crescimento de Cff em algumas placas, este fato pode estar relacionado à maior capacidade de produção de substâncias inibitórias com ação antibacteriana. No entanto, ressalta-se que a antibiose, apesar de ser uma característica importante para o biocontrole, é apenas um dos mecanismos usados por microrganismos (5).

No ensaio da colonização do rizoplano, após observações diárias dos tubos, e aos 10 dias após a incubação, verificou-se que não houve colonização das raízes de plântulas de feijoeiro-comum pelos isolados avaliados (Tabela 2). O estabelecimento bacteriano na rizosfera é fundamental para que o microrganismo possa interagir com a planta. A inconstância dos resultados é citada por diversos autores, pois nem sempre as bactérias repetem sua atuação como promotoras de crescimento, mesmo em testes realizados em condições semelhantes $(3,4)$.

Apesar de não ser observada a colonização das raízes pelas bactérias, foi possível inferir que alguns tratamentos proporcionaram resultados superiores. Os tratamentos com $B$. subtilis e $B$. subtilis (AP03) promoveram maior porcentagem de germinação das sementes, não diferindo da testemunha (Tabela 2). O tratamento com Rhizobium sp. apresentou menor porcentagem de plantas emergidas. Dentre as vantagens proporcionadas por B. subtilis está à relacionada à germinação mais rápida das sementes. Manjula $\&$ Podile (8), trabalhando com sementes de feijão-guandu tratadas com formulação a base e $B$. subtilis AF1 em turfa suplementada com quitina, verificaram que houve um aumento da emergência e peso seco das mudas de 29 a $33 \%$.

Não houve diferença no desenvolvimento das plântulas, quanto ao comprimento da raiz e da parte aérea, promovido pelas bactérias ensaiadas. Entretanto, esse fato pode ser explicado pela pouca idade e as condições de desenvolvimento das plântulas em Phytogel-água, pois em condições de crescimento em substrato há registros do incremento da biomassa de plantas de feijoeiro (10). Com os resultados obtidos foi possível identificar o potencial in vitro de isolados de Bacillus sp. no controle da murcha-de-curtobacterium em feijoeiro-comum.

Tabela 1. Teste de antagonismo, pela técnica de dupla camada, realizado com Bacillus sp. contra Curtobacterium flaccumfaciens pv. flaccumfaciens (Cff).

\begin{tabular}{lcc}
\hline \multirow{2}{*}{ Tratamentos } & & Cff \\
\cline { 2 - 3 } & Isolado 2500 & Isolado 2628 \\
\hline Bacillus subtilis & +++ & ++ \\
Bacillus subtilis (AP03) & ++++ & +++ \\
Bacillus licheniformis & ++++ & ++++ \\
B. subtilis + B. licheniformis & +++ & +++ \\
\hline
\end{tabular}

*Classificação da capacidade de inibição com base no diâmetro do halo de inibição: $+(0-0,9 \mathrm{~cm})$; ++ $(1,0-1,9 \mathrm{~cm})$; +++ $(2,0-2,9 \mathrm{~cm})$; ++++ (>3,0 cm).

Tabela 2. Efeito do tratamento de sementes de feijão-comum (Phaseolus vulgaris L.) com isolados de bactérias sobre a emergência de plântulas, colonização e comprimento da raiz e da parte aérea.

\begin{tabular}{|c|c|c|c|c|}
\hline Tratamentos & \% plântulas emergentes & Colonização de raízes & \multicolumn{2}{|c|}{ Comprimento (cm) } \\
\hline Bacillus subtilis & 100 & $\mathrm{nc}^{*}$ & $7,91 \mathrm{a}^{* *}$ & $7,62 \mathrm{a}$ \\
\hline Bacillus subtilis (AP03) & 100 & $\mathrm{nc}$ & 7,43 a & $7,25 \mathrm{a}$ \\
\hline Bacillus subtilis + Bacillus licheniformis & 90 & $\mathrm{nc}$ & $7,96 \mathrm{a}$ & $7,71 \mathrm{a}$ \\
\hline Rhizobium sp. & 82 & $\mathrm{nc}$ & $7,87 \mathrm{a}$ & $7,75 \mathrm{a}$ \\
\hline Testemunha & 100 & $\mathrm{nc}$ & $5,96 \mathrm{a}$ & $7,62 \mathrm{a}$ \\
\hline
\end{tabular}

*nc - não visualização da colonização das raízes pelos tratamentos testados; **Médias seguidas pela mesma letra na coluna não diferem estatisticamente pelo Teste de Tukey a $5 \%$ de probabilidade 


\section{REFERÊNCIAS}

1. Avaci, A.B.; Coelho, S.R.M.; Nóbrega, L.H.P.; Rosa, D.M.; Christ, D. Qualidade fisiológica de sementes de feijão envelhecidas em condições de alta temperatura e umidade relativa. Publicativo UEPG - Ciências Exatas e da Terra, Agrária e Engenharias, Ponta Grossa, v.16, n.1, p.33-38, 2010.

2. Behlau, F.; Nunes, L.M.; Leite JR., R.P. Meio de cultura semi-seletivo para detecção de Curtobacterium flaccumfaciens pv. flaccumfaciens em solo e sementes de feijoeiro. Summa Phytopathologica, Botucatu, v.32, n.4, p.394-396, 2006.

3. Freitas, S.S.; Melo, A.M.T.; Donzeli, V.P. Promoção de crescimento de alface por rizobactérias. Revista Brasileira de Ciências do Solo, Viçosa, v.27, n.1, p.61-70, 2003.

4. Huang, H.C.; Erickson, R.S.; Hsieh, T.F. Control of bacterial wilt of bean (Curtobacterium flaccumfaciens pv. flaccumfaciens) by seed treatment with Rhizobium leguminosarum. Crop Protection, Oxford, v.26, p.10551061, 2007.

5. Lanna Filho, R.; Ferro, H.M.; Pinho, R.S.C. (2010) Controle biológico mediado por Bacillus subtilis. Revista Trópica, Chapadinha, v. 4, n. 2, p. 12-20, 2010.

6. Lazzareti, E.; Bettiol, W. Tratamento de sementes de arroz, trigo, feijão e soja com um produto formulado a base de células e de metabólitos de Bacillus subtilis. Scientia Agricola, Piracicaba, v.54, p.89-96, 1997.

7. Lucon, C.M.M.; Akamatsu, M.A.; Harakava, R. Promoção de crescimento e controle de tombamento de plântulas de pepino por rizobactérias. Pesquisa
Agropecuária Brasileira, Brasília, DF, v.43, n.6, p.691-697, 2008.

8. Manjula, K.; Podile, A.R. Increase in seedling emergence and dry weight of pigeon pea in the field with chitin-supplemented formulations of Bacillus subtilis AF 1. World Journal of Microbiology \& Biotechnology, Hull, v.21, p.1057-1062, 2005.

9. Maringoni, A.C.; Rosa, E.F. Ocorrência de Curtobacterium flaccumfaciens pv. flaccumfaciens em feijoeiro no Estado de São Paulo. Summa Phytopathologica, Botucatu, v.23, p.160-162, 1997.

10. Martins, J.S.; Medeiros, F.H.V.; Souza, R.M.; Resende, M.L.V.; Ribeiro Júnior, P.M. Biological control of bacterial wilt of common bean by plant growth-promoting rhizobacteria. Biological Control, Orlando, v.66, p.6571, 2013.

11. Queiroz, B.P.V.; Aguilar-Vildoso, C.I.; Melo, I.S. Visualização in vitro da colonização de raízes por rizobactérias. Summa Phytopatologica, Botucatu, v.32, p.95-97, 2006.

12. Rava, C.A.; Costa, J.G.C. Reação de cultivares de feijoeiro comum à Murcha-de-curtobacterium. In: Reunião Sul-Brasileira de Feijão, 5; Reunião Anual Paranaense de Feijão, 2001, Londrina Anais. Londrina: Instituto Agronômico do Paraná, 2001. p.55-56.

13. Romero, R.S. Bactérias fitopatogênicas. 2. ed. Viçosa: Editora UFV,2005. $417 \mathrm{p}$.

14. Silva, J.R.C.; Souza, R.M.; Zacarone, A.B.; Silva, L.H.C.P.; Castro, A.M.S Bactérias endofíticas no controle e inibição in vitro de Pseudomonas syringae pv. tomato, agente da pinta bacteriana do tomateiro. Ciência Agrotecnologia, Lavras, v.32, n.4, p.1062-1072, jul./ago. 2008. 